\section{Forladte romerske alpeveje En Rejseerindring fra Midsommer 1885}

\author{
afbotanikeren, dr. Emil Petit \\ Udgivet afGrå Borup-Nielsen
}

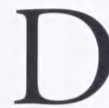

en mægtige Skranke, der med den høje langstrakte Alpekjæde var rejst mellem Italien og hele den Nord for liggende Del af Europa, havde alt tidligere (under den 2. puniske Krig) med Hannibals dristige Tog, der sandsynligvis udgik fra Isères Dalen og over den lille St. Bernhard, viist sig som overstigelig selv for større Menneskemasser, men længe derefter vedblev den dog at være en alvorlig Hindring for Barbarernes Indfald og et Værn for den republikanske Romerstat. Selv da denne ved Overgangen til Kejsertiden havde begyndt at udvide sig til Transalpinien, søgte man længe at undgaa den saare vanskelige Fremtrængen ad Alpepassene, og den langvarige Kamp med de germanske Folkestammer førtes væsentligt fra den galliske Side, der naaedes tilsøs eller langs Foden af de maritime Alper.

\section{Paa lignende Maade udgik} Kejserstatens Udvidelse til Donaulandene fra den græske Halvø, hvortil foruden $\mathrm{S} ø$ vejen ogsaa en Landevej, der snart udviklede sig til en Hovedvej (Via Aemilia) fra det Venetianske benyttedes. At Alpeovergange selv af større Hærmasser af og til fandt Sted, er ubestrideligt, men til Anlæg af virkelige Kunstveje paa disse kom det næppe, førend Aquileja begyndte at opnaa den store Betydning som Knudepunktet mellem den vestlige og østlige Del af Romerstaten.

Trangen til en mere direkte For- bindelse mellem denne By, der med sin Beliggenhed hurtigt udviklede sig til en af de største Handelspladser, og som snart skulde vise sig som Roms vigtigste Bolværk, og de nordlige Provinser (Rhætia, Voricum og Pannonia) overvandt Naturhindringerne, der her i de juliske og karniske Alper, hvis Højder gjennemgaaende vare noget lavere og hyppigere gjennembrudt af Vandstrømme, viste sig lidt mindre besværlige at overkomme. Senere og især hen i Middelalderen banede der sig under den tiltagende Samfærdsel visse bestemte Linier ogsaa over de mere centrale Alper, hvor selve Transporten med Trækdyr kunde foregaa, dog var det først vort Aarhundrede forbeholdt ikke alene at bygge stolte kunstfærdige Kjøreveje over de vanskeligste Passer, men endog at bore sig Vej tværs gjennem selve Bjergkolosserne.

Tiberstrøm bortskyllede efterhaanden det Meste af, hvad den antikke Verden havde skabt, den historiske Udvikling forlagdes hen til andre Skuepladser, men næppe nogetsteds traadte Forvandlingen hurtigere og mere iøjnefaldende frem end ved Aquileja, som alt 452 blev lagt i Grus af Attila og tildels gjenopbygget atter led størst under Gotherne og Longobarderne, og hvis fuldstændige Forfald kun en kort Tid forhaledes ved det dersteds oprettede Patriarkat. Ogsaa det hele rige, tætbefolkede Opland blev forladt og forglemt, idet tillige Naturmagterne efterhaanden greb ind og lagde et bredt alluvial Bælte af usunde Maremmer udenfor. Det derpaa opblomstrende Venedig trak Menneskestrømmen til sig og banede sig nye Veje over Alperne, medens de gamle, mere østerpaa, forfaldt.

Medens Venedig og senere ogsaa Triest bleve de to Havneknuder for al Handel og Vandel mellem Vest og Øst, og Ad- 


\section{T.2500}

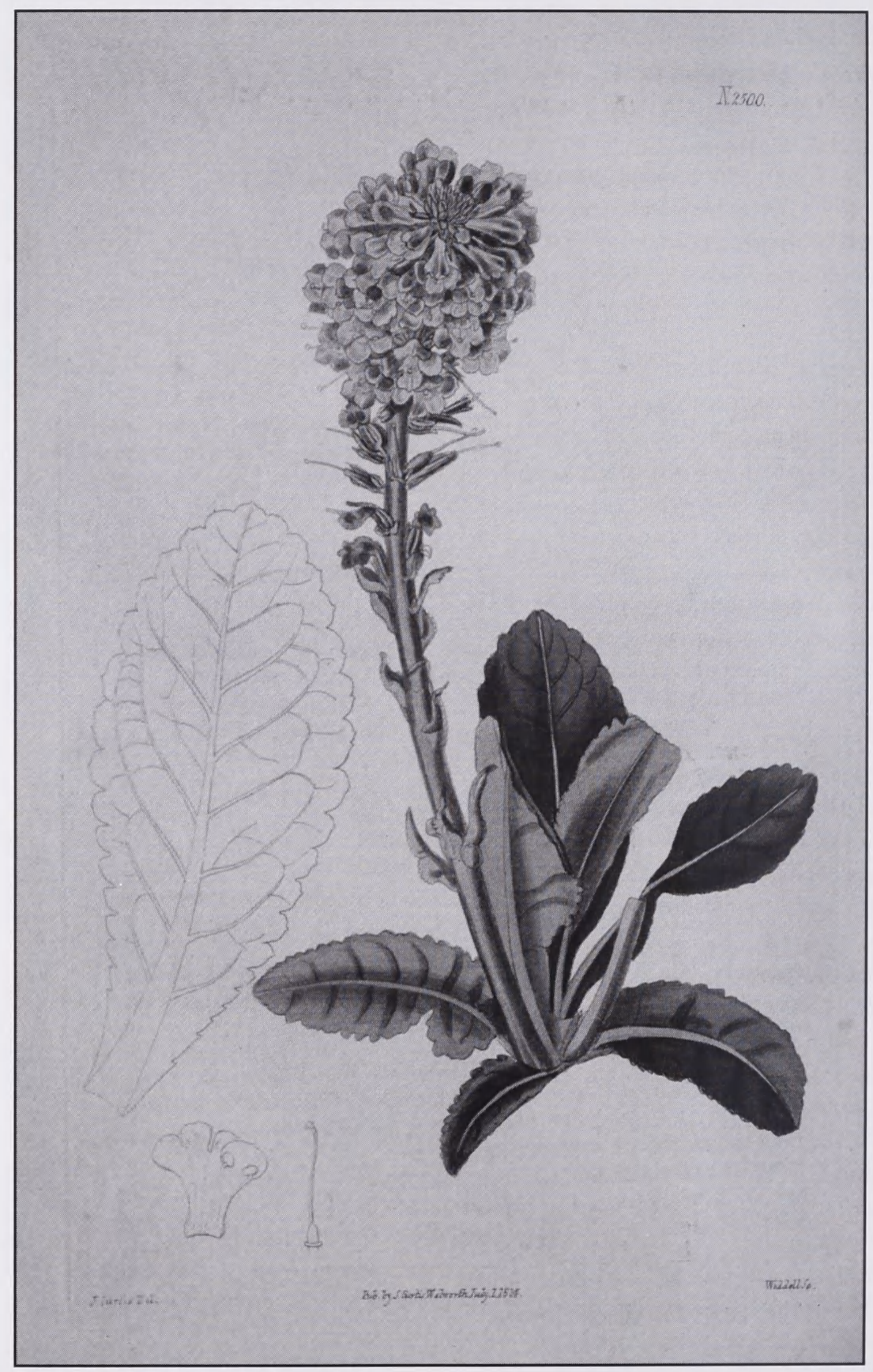

Wulfenia carinthiaca. Curtis Botanical Magazine, tavle 2.500, bind 51. Foto: Botanisk Museum, Christian Lange. 
gangene til disse to Punkter over Alpekjæden efterhaanden bleve mere passable, sank det mellemliggende Terrain, det af Naturen i mange Henseender begunstigede Landskab Friaul hen i Forglemmelse, og først for et par Aar siden blev den besværlige Adgang nordfra til det lettet noget ved PontebbaBanen. Paa en botanisk Exkursion iaar kom jeg uforvarende paa en Vej, der nu næsten er ufremkommelig, men om hvilken deter godtgjort, at den i Romertiden var en af de vigtigste Forbindelsesveje mellem Aquileja og Drau-Dalen. Det var nærmest en enkelt Plante, (Wulfenia carinthiaca) der kun forekom paa et meget indskrænket Gebet, der lokkede mig ind i et vildt og vanskeligt tilgjængeligt Parti af de karniske Alper, hvor disse danne Grænsen mellem Kärnthen og Italien.

Jeg havde forladt Pusterthalibanen ved Ober-Drauburg, hvorfra en god men stejl Kjørevej hinsides Draufloden fører over Kötschach-Pas ned i den brede Gailedal, hvor Vejen ved den fattige Landsby Mauthen pludselig syntes at stoppe. Kjøbmanden, hos hvem jeg overnattede, erklærede først, at jeg kun til Fods kunde naa op til Plöckenpas, men da jeg viste ham min Bagage, lod han sig overtale til næste Morgen at stille en Kærre med en stor, stærk Hest for, tilføjende den Betingelse, at jeg på de vanskeligste Punkter maatte stige af og hjælpe det lille Kjøretøj over dem. Hvad det forste angik, viste det sig strax ved Opstigningen ovenover Landsbyen nødvendigt, og senere, hvor Kusken, der under hele Passagen gik ved Hestens Hovede førende den i Bidslet, opfordrede mig til at sætte mig op, var det en saa radbrækkende Motion over den med større eller mindre Klippestykker besaaede Vej, at hele Bagagen oprørtes derover og flere Gange hoppede ud af Kærren. Viste Turen op ad Bjerghøjden

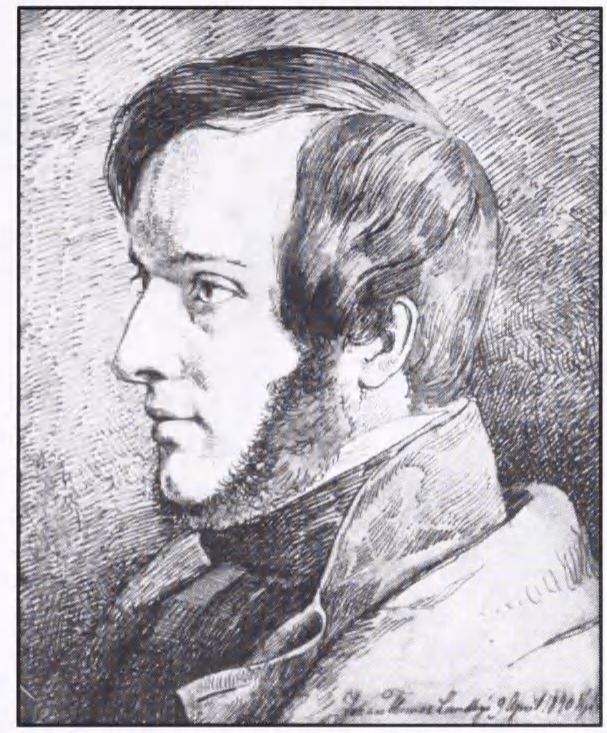

Emil Petit. Tegning fra 1848 af J. Th. Lundbye. Efter fotograf $i$ Det Kongelige Bibliotek.

sig paa den Maade som en Fodtur, glemtes dog alle Møjsommeligheder over Naturens henrivende Skjønhed. Vejen snoede sig langs en brat, dyb Bjergkløft, der paa begge Sider var skovklædt - og fra hvis Bund man hørte den skummende Elv bruse. Skovvæxten paa de østlige Alper viser langtfra den Ensformighed, som i de vestligere dele af Kjæden og er tillige i disse afsidesliggende Egne mere uberørt af Menneskehaand. I den lavere Bjergregion blande sig Ædelgran og Fyr med Ege, Ahorn, Ask og andre Løvtræer, der højere oppe afløses af udstrakte Bøgeskove, mellem hvilke snart derpaa Grupper af Rødgran og Lærketræer skaffe sig Plads, indtil de førstnævnte sluttende sig øverst oppe til Crumholz, blive Eneherskere. Den største del af vor Vej snoede sig hen under 100 aarige Bøge med tæt Underkrat af Hyld, Hassel, Berberis, Liguster o.a. mellem hvilke Fingerbøl og Stormhat stak deres lange (for gule) Blomsterklaser frem, medens den smukke røde Skovlilie antydede 
Kalkgrunden. Halvraadne Granstammer vare lagte hen over de af optøende Smaabække dannede Spalter, hvor Vogntøjet kun med stor Varsomhed kunde føres over, medens der til Værn mod den bratte Afgrund kun hist og her var fældet et Træ. Til Brændehuggerens Øxe saas ellers intet Spor, og kun etsteds paa den 4 Timer lange Vandring traf vi en lille Bondegaard med nogle Græsgange, til hvilken der var knyttet lidt Krohold, i al Fald kaldte den sig "Zum lustigen Gränzer”. Oppe paa selve Pashøjden (ca 3500') ligger et Sæteri (“Alm”) i den græsrige Dal og mellem de blomstersmykkede Bjergskraaninger ("Matten"), og vare Forholdene end, hvad Logi og Kost angik, kun tarvelige dér, var jeg dog glad ved dette bequemme Landquarter for mine Exkursioner.

Rundtom hævede Fjeldene deres nøgne, takkede Tinder til 6 à 7000 Fods Højde, paa et Par Steder i Nærheden behøvede jeg kun at stige 5 à 600 Fod tilvejrs for at naa hen til endnu (i Begyndelsen af Juli) usmeltede Snepletter og den dertil knyttede alpinske Vegetation. Medens man i Schweiz maa langt højere op for at træffe en saadan, er det i de østlige Alper paafaldende, hvor langt dybere den vokser ned. Som bekjendt varer Vinteren meget længere i det østlige Kontinent, Sneen smelter først sent; og i Stedet for den varme Føhn optræder i disse Egne den barske Bora. Hyppigere end hist føres Alpeplanterne hen dels af Vandstrømmene, men især paa det nedglidende "Gewölk", der fra ret i disse Bjerge fremherskende, let-spaltelige Kalksten og Skifer, i Masser løsner sig fra de karpetakkede Tinder, langt ned i de lavere Egne. Ikke at tale om, at man her ikke sjældent træffer Alperoser ved ca 2000 Fod, vil jeg blot som Exempel nævne Edelweiss (Leontopodium) en af de øverste, der agerer som Kjendetegn for den dristige Alpebestiger, men hvoraf jeg her i Østerrig flere Steder er stødt paa Flygtninge nede i Dalen.

En Fjerdingsvej Syd for Gaarden naar man selve Pashøjden med Vandskjellet for de mod Øst til Donau og de mod Syd til Adriaterhavet søgende Strømme, og det paa dette Sted saa snævre Defilé var gjort passabelt ved tydelige Klippesprængninger, men at disse maatte godskrives en længst forgangen Tid, fremlystes aabenbart af to romerske Indskrifter, der ikke langt fra hinanden fandtes indhuggede i Klippevæggen. Disse vare rigtignok af Tidens Tand saa udviskede, at det for en usagkyndig som mig var umuligt at descifrere dem, ej heller har jeg kunnet opspore en Tydning af dem, men om deres Ægthed er der ingen Tvivl ligesaalidt om Færdslens Betydning i gamle Dage ad denne Alpevej.

Fra Aquileja fulgte den Tagliomento-Flodens Løb til Tolmezzo, derefter en Biflod af denne til Paluzza, den ved vort Pas nærmeste italienske By, og fortsatte sig saa - rigtignok i en langt mere farbar Skikkelse end den, hvori den nu forefindes - til Drau-Floden, hvor den romerske Station Longium (det nuværende Lienz) var Endemaalet. Tæt nedenfor Defiléet overskrides den italienske Grænse. Kun betegnet ved en Pæl, og herfra ind til Paluzza kan dog et Kjøretøj med mindre Besvær komme frem. Et Toldsted findes ikke heroppe, thi Transport pr Age standser jo ved Sæteriet og de eneste Varer, hvis Omsætning mellem de to Riger, jeg blev Vidne til, vare af og til en Sæk Hvedemel, den fattige Italiener havde hentet nede i Gailedalen og nu slæbte paa sin Ryg ad den lange besværlige Vej til sit Hjem hinsides Passet, eller Brædder fra et Savskjæreri i en af Sidedalene, hvoraf en Række unge, opskjørtede Piger hver bar et stort og langt balancerende paa Hovedet ned til Paluzza. 
Mærkeligt var det at forestille sig, at der her i fordums Tid havde hersket Liv og Røre, hvor man nu var afskaaren fra al Forbindelse med Yderverdenen og - (for ikke at tale om det Spindelvæv, Telegraftraaden) ikke engang et Landpostbud kunde finde hen. En dyb og stille Fred var udbredt over dette storartede Landskab, hvor Forbindelsen med Himlen opad Alpetoppene syntes nærmere end med det menneskelige Samfund og dets Indretninger, Stilheden afbrødes kun af og til af en Klokkeklang fra de omvankende Køer eller om Aftenen, naar Skumringen faldt paa, og kun Bjergtinderne endnu lyste i Solglans, af Hyrdens Horn eller Karlens melodiske "Jauken" op i Fjeldet.

Saa meget mere overraskedes jeg en Dag, jeg halvt blundende laa ved en Bæk mellem Kartheuser Nelliker, garnioliske Alpeliljer og stærkt duftende Alperanuncel og hele den brogede Verden, Engene her ere smykkede med, ved pludseligt at se en østerrigsk Gendarm ved min Side, og strax randt mig i Hu den Skjæbne, der for en Del Aar tilbage havde ramt Schweizer-Botanikeren Vulpius i disse Egne. Tilfods blev han slæbt den lange Vej til Klagenfurt, hvor han holdtes 3 Dage i et elendigt Fangehul, ja! Selv en østerrigsk Adelrad, Friherre v. Hohenbükel, blev paa sine botaniske Exkursioner 3 Gange arresteret. Men om de forandrede Tider vidnede strax Tiltalen: "Hab' die Ehr'" og hans hele høflige Optræden, medens det dog i Samtalens Løb blev mig tydeligt, at han uformærkt havde udspejdet hele min Færd den foregaaende Dag. At Politi ogsaa i dette Paradis kan være nødvendigt, fremgik ogsaa af det Jerngitter, hvormed alle Vinduer i Sæteriets Hovedbygning vare forsynede, da Indbrud og Overfald fra de italienske Bjergnaboer ikke vare uhørte. -

$$
\text { Medens man med den nye }
$$

Pontebba-Bane kun ad en Omvej (over Udini) kan naa ind i Grevskaberne Görz og Gradiska, falder den direkte gamle Passage fra Tarvis over Predil-Passet ned i Isonzos vide maleriske Dal endnu i nogenlunde farbar Stand, ventende paa den her længe projekterede Bane. At ogsaa denne Vej alt i Romertiden benyttedes til at naa Drauflodens Gebet er rimeligt nok; den brede, frugtbare Dal langs Kourstens vestlige Side frembød fra Adriaterhav ind til Görz ingen Vanskeligheder, og de Klippemasser, der herfra træde nær til Flodens Løb, naar ikke nogen betydelig Højde, først ved Flitscher Klause taarner de juliske Alper sig op, og det snævre Pas her ved Koritenza. Elreso, hvor Østerrigerne i den seneste Tid have opført en lille, men stærk Fæstning, frembød næsten den største Hindring, skjønt den sidste meget stejle Opstigen af Predil $\left(4000^{\prime}\right)$, hvor man atter møder et østerrigsk Fort, heller ikke var magelig. Det er iøvrigt en af de smukkeste Alpeveje, man kan passere. Sydens Frugttræer og en rig Vegetation ledsage den Rejsende et langt Stykke paa Vejen, men naar man ved Caporetto (Karfreit) har maattet ombytte Postchaisen med den lettere Kabriolet og temmeligt pludseligt her skiftet det italiensktalende med det sloveniske Folkefærd, træder først den øvre Bjergzones Højkam med sine Løvog Naaleskove een i møde, hvorefter Dolomitternes vældige Brudmasser og kaotisk kløftede Fjelde taarner sig op til en Højde af over 8000 Fod.

Fra Predil-Passet kommer man ned til en yndig, stille Bjergsø i Nærheden af Byen Raibl med en betydelig Bjergværksdrift (Zink og Bly) og langs den over Hals og Hoved fremstormende Schlitze-Elv til Tarvis. Denne Landsby, hvor jeg for 10 Aar siden kun forefandt et tarveligt Einkehrhuus bei Fillafer, og hvor jeg af Rejsende kun saa 
Masser af ventiske Bønder, der valfartede til Luschariberg (en Hyrde havde for 500 Aar siden fundet et Maria-Billede deroppe, for hvilket Faarene knælede), havde nu faaet et helt civiliseret Præg, foruden det store Antal af Passanter lokkede den farlige Beliggenhed nedenfor den mægtigste af Karawenkerne, den stolte Mangart og tæt ved den uforlignelige Schlitze-Slugt, hvor en dristig Klippesti er bygget langs den stejle Fjeldside over den brusende Elv, ogsaa mange Turister til et længere Ophold. Udenfor Tyskland og Østrig er Stedet imidlertid endnu ikke synderligt kjendt, af Landsmænd har dog Holger Drachmann alt for et par Aar siden opdaget det, og jeg traf ham der siirligt indrettet i et Bondehus. Men hans Have var mindre fortrolig, men om "den Dichter" vidste høje og lave Besked, han lod til at være meget populær i Egnene.

I denne havde han selv ret levet sig ind, og det er saa Forklaringen, at denne højstemte, lyriske Aand maatte staa i et inderligt, sympathisk Forhold til denne storartede Natur, i hvis stille Skjød hans Harpe uforstyrret fik lov at tone altid dog sagt om Danmark. Ret som en nordisk Huldres Sang, lød Schlitze-Flodens Toner (i Schlitzekløften).

For den ensomme Vandrer var dette yndige Familiehjem, hvor dansk Tarvelighed var parret med ligefrem Hjertelighed, en glad Overraskelse, og med ikke mindre Glæde fik jeg under Samtaler Bekræftelse paa, hvad de seneste Arbejder alt havde antydet, hvor lutret og modnet denne højtbegavede Digteraand er gaaet ud af Kampen. Til Efteraaret agtede han at flytte tilbage til Danmark; paa to prægtige Drenges Skolegang var det snart Tid at tænke, dog syntes ogsaa Længslen at være den egentlige Drivfjeder.

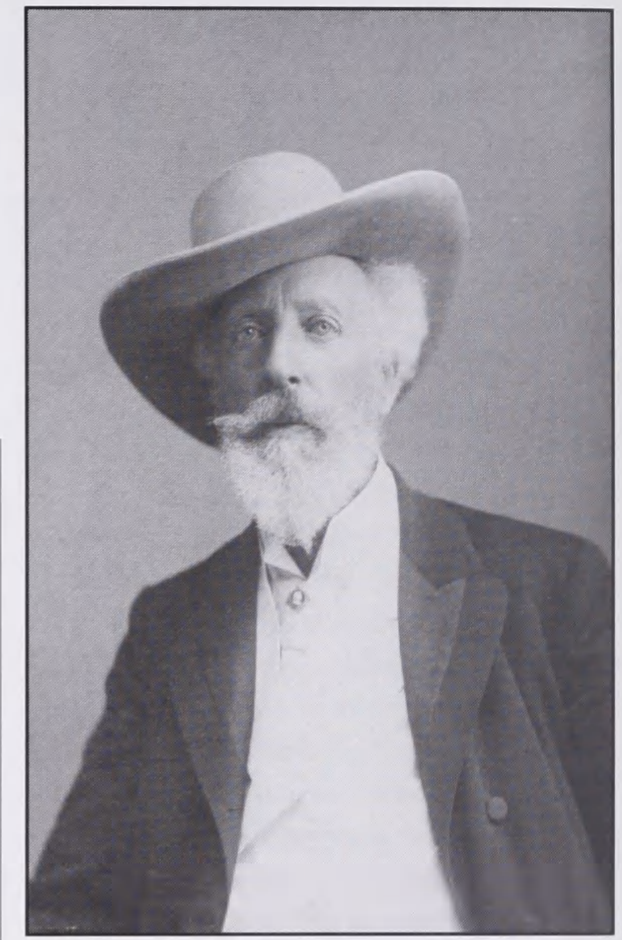

Digteren Holger Drachmann, som Emil Petit traf på sin vandring.

Ogsaa i denne Egn skulde jeg støde paa et Spor af en romersk Alpevej, men her var dette saa udvisket, at i Grunden kun Navnet “die Römerstrasse" var blevet tilbage, og man derfor har stor Vanskelighed ved at angive dens Udgangs- og Endepunkt. Med Navnet betegnes nu for Tiden ikke en egentlig Vej, men kun en lang Dalstrækning, østlig for Tarvis, som man efter en halv times Vandring ad Fodstier over et bakket Terrain naar hen til. Her gjælder det om først at finde sig tilrette i en tæt og vidtudstrakt Granskov, der er gjennemkrydset af Trætransportens Hjulspor, men efter en halv Times Forløb forsvinde disse, Dalen indsnævres, sammenfiltret Krat blande sig mellem Træerne, for det meste forkrøblede Bøge, og efterhaanden bliver det umuligt at arbejde sig videre frem 
ad den tætbevoxede og ujævne Bjergside, min lille Fører vidste i al Fald ikke Besked om nogen Sti, der førte op over Passet.

For at komme videre frem var der ingen anden Udvej end at søge ned i det for Tiden temmeligt udtørrede Flodleje, der fyldt med løse Rullesten og hist og her næsten spærret af nedrullede Klippestykker gjorde Fremmarchen yderst trættende. Mørke og truende hævede Bjergkolosserne sig til begge Sider og sluttede sig til sidst sammen i en cul de sac, for hvilken en af Egnens Beboere vel ikke viger tilbage, men som tvang mig til at vende om. Her har virkelig existeret en af Romerne anlagt Vej, men man tilstaar, at de ikke have ladet sig skræmme af Naturhindringer, der med deres mangelfulde Hjælpemidler næsten kunne synes uoverkommelige, medens paa den anden Side deres ringe topografiske Indsigt stundom har ført dem paa Afveje. Rimeligst synes det at antage, at denne "Römerstrasse" har ført langs Weisenbach hen til Rauflodens Kilder og derfra ned i denne frugtbare Dal, hvor nu Rudolfsbanen fører til Krains Hovedstad Laibach. - Det her nu næsten utilgjængelige Overgangssted hedder Römer-'Pas'og fører ned mod Gailefloden, der maa overskrides for at naa hen til Villach, et Centralpunkt i de karniske Alper, hvor for Tiden tre Jernbaner støde sammen, og som tillige angiver Grænsen for det Sloveniske, der her er i stærk Brydning med det Tyske.

Skjønt den Danske møder hint undertrykte Folkefærd med Sympathi, føler man sig ikke tiltalt af disse mørke, ofte noget skumle Fysiognomier med grove, uregelmæssige Ansigtstræk, og i Modsætning til de tyske Østerrigeres venlige Forekommenhed bliver deres tvære og frastødende. Næsten endnu mere paafaldende, hvorved det dog maa tages i billig Betragtning, at man ved $\mathrm{i}$ Reglen at være nødt til at tiltale dem paa Tysk af dem straks henfores til denne dem forhadte Race. Dog ogsaa for de tysktalende Osterrigere er der Grader i deres Optræden ligeoverfor Fremmede, saaledes sige Tyroleren, der selv ofte er noget mut, om den tydsktalende Kärnther: “er is eben ein grober Kärnther,” og disse trøste sig da igjen med Udraabet: "Warten Sie bis zu die Wendischen kommen.” 